\title{
A 'Farewell' to Arms
}

Dear Readers,

The 2007 publication year begins a new era in the history of Clinical Medicine \& Research; one that will be led by my successor as Editor-in-Chief, Kurt D. Reed, MD. Dr. Reed has been an editorial board member since the journal's restructuring in 2002 and an avid supporter of its efforts. A clinical pathologist by training, he is also actively involved in emerging infectious disease and zoonotic research, and notably, was one of the investigators who first identified the monkeypox virus in the Western Hemisphere in 2003. I welcome Dr. Reed to his new role as Editor-in-Chief, and it is in his capable hands that I leave the journal.

It has been my sincere pleasure and privilege to be a part of Marshfield Clinic's scholarly publications. During the 10 years I served as Editor-in-Chief, I have been involved in the evolution of Marshfield Clinic's scholarly publications from a small 'house' publication to the current format as a rigorously peer reviewed, internationally indexed medical journal with an international audience. Restructuring the journal into its current format was no small feat and would not have been possible without the guidance, hard work and dedication of many individuals to whom I am grateful for helping the journal achieve these successes. Specifically, I wish to thank the members of the editorial board for their expert advice and guidance on restructuring the journal into one that is scientifically sound, pertinent, timely and readable; Barbara Bartkowiak, MLIS, MST, Marshfield Clinic Research Librarian, for helping the editorial board understand the intricacies of the scholarly standards necessary for inclusion in the US National Library of Medicine's Index Medicus/MEDLINE database; the former Senior Editors, Rebecca Normington for helping with the initial preparations for restructuring the journal, and Gwendolyn Strampp, MS, for the long hours she dedicated to developing the Information for Authors document, Copyright Transfer Agreements, Conflict of Interest declarations, peer review standards, and the journal's initial web site, all of which were critical to establishing the journal as a credible medical resource and one that meets the standards of many indexing organizations; Sherry Salzman Scott, the journal's current Senior Editor, for her hard work at recruiting original articles that provide groundwork for improved clinical practice, for increasing the journal's visibility through the establishment of a new, highly visible, easily accessible, user-friendly Web site, and for working to achieve inclusion in Index Medicus/MEDLINE, PubMed Central, EMBASE and SCOPUS. And to all the individuals, past, present and future, who serve as peer reviewers for our articles, I owe a debt of thanks. It is through your effort, solely based on your dedication to the advancement of medical science, that the journal can ensure the articles we publish are original, scientifically sound, credible and useful.

To the authors, most especially those who submitted their work prior to the journal's indexing in Index Medicus/MEDLINE, thank you for your trust that Clinical Medicine \& Research would become indexed and that your work would be widely available to the medical community. Lastly, to the readers of Clinical Medicine \& Research, thank you for your interest in our work. I hope you have found our articles to be timely, interesting and credible. It has been my pleasure to help bring them to you.

Thanks for the ride!

Richard A. Dart, MD

Editor-in-Chief 